Copyright (C) 2018 by Academic Publishing House Researcher

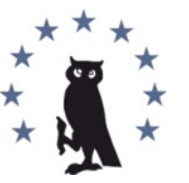

Published in the Russian Federation

European Researcher. Series A

Has been issued since 2010.

ISSN 2219-8229

E-ISSN 2224-0136

2018, 9(3): 249-258

DOI: $10.13187 /$ er.2018.3.248

www.erjournal.ru

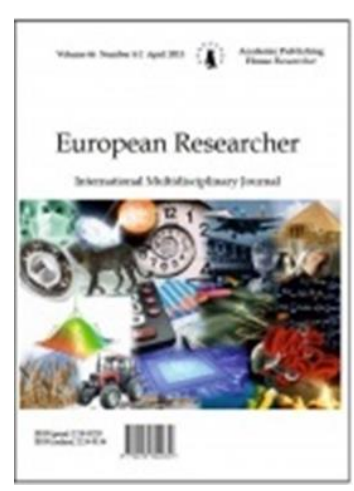

\title{
The Hermeneutic Analysis of Italian Feature Films about the School
}

\author{
Roman V. Salny a , *
}

a Rostov State University of Economics, Russian Federation

\begin{abstract}
The analysis carried out in the article makes it possible to trace the transformation of the images of a schoolboy, teacher and family relations on an Italian screen. The solution of this problem was facilitated by: the study of the cultural, social, political context and economic state; the analysis of ideology, including the influence of the Catholic religion on the cinema; analysis of genre stereotypes.

The article describes the character of social and cultural transformations in Italy, their influence on child-parent relations, world view of schoolchildren and their attitude to traditions and values are analyzed. Historical examples are presented reflecting the change of ideology, the loosening of patriarchal foundations, the changing role of women, the sexual revolution, which had a tremendous impact on the image of a schoolchild's in Italian cinema. Examples of representations by the authors of images of Italian schoolchildren in the cinema in various genre forms are given: from author dramatic to commercial comedian and erotic.

The article concludes that over time, schoolchildren on the Italian cinema screen became more freethinking and selfish. In most Italian films, they expressed individual freedom in various forms of protest. In the 1960s, they resisted pedagogical influence and authoritarianism of teachers and parents. In the 1970s and 1980s, cultural prohibitions on the open expression of sexual desires were overcome. In the 1990 s they demonstrated a subjective attitude towards moral principles, protested against "absolute truth".
\end{abstract}

Keywords: cinema, Italy, school, hermeneutic analysis, media education, representations, values, culture.

\section{1. Введение}

Социокультурные преобразования в Италии отразились на детско-родительских отношениях, мировоззрении школьников, их отношении к традициям и ценностям. Смена идеологии, расшатывание патриархальных устоев, изменение роли женщины, сексуальная революция оказали колоссальное влияние на образ школьника в итальянском кинематографе. Авторы репрезентировали его в различных жанровых формах: от авторских драматических до коммерческих комедийно-эротических.

Проведенный в статье анализ позволяет проследить трансформацию образов школьника, учителя и семейных отношений на итальянском киноэкране. Решению этой задачи способствовали: изучение культурного, социального, политического контекста и

\footnotetext{
${ }^{*}$ Corresponding author

E-mail addresses: roman_tag82@mail.ru (R.V.Salny)
} 
экономического состояния; анализ идеологии, в том числе влияния католической религии на кинематограф; анализ жанровых стереотипов.

\section{2. Материалы и методы}

Материал исследования - итальянские игровые фильмы школьной тематики, проведен герменевтический анализ (Эко, 2005: 209; Бэзэлгэт, 1995; Silverblatt, 2001: 80-81) итальянских аудиовизуальных медиатекстов о школе, который, на наш взгляд, особенно важен для медиаобразовательных задач при обучении будущих историков, культурологов, искусствоведов, социологов, филологов, теологов, психологов, педагогов.

\section{3. Обсуждение}

За исключением десятка фильмов комедийно-эротического жанра (вышедших в прокат в 1970-х - 1980-х годах) в Италии за последние 70 лет было снято относительно небольшое количество на тему школы: «Учитель из Виджевано» (1963, режиссер Э. Петри), «Все в школу» (1979, режиссер П.Ф. Пингитор), «Школьная поездка» (1983, режиссер П. Авати,), «Я надеюсь, что выкарабкаюсь» (1992, режиссер, Л. Вертмюллер), «Школа» (1995, режиссер, Д. Луккети), «Приветствие профессора» (1997, режиссер, Р. Милани). Образ школьников в них раскрывался в двух аспектах. В одном случае школьники были показаны отчужденными, одинокими или активно протестующими против позиции и поведения учителей, в другом - равнодушными к окружающим и активно репрезентирующими образ собственного Я.

В итальянских неореалистических фильмах 1940-х - 1950-х годов дети «страдают во взрослом мире» (Ж. Делез). Тема отчуждения детей и родителей определила основную драматургическую линию итальянского кинематографа о детях и школьниках этого периода. Еще в 1943 году В. Де Сика снял фильм «Дети смотрят на нас». В ней глазами четырехлетнего мальчика показано разрушение семьи.

Как ни странно, но итальянские кинематографисты в этот время не сняли ни одной картины, рассказывающей о тайных мечтах детей, их эмоциональных переживаниях, экзистенциальных проблемах. Ведущую роль в фильмах о школьниках играла социальная критика. Аналогичные тенденции можно проследить и во французском кинематографе: «восстание мальчиков против правил, наложенных репрессивным образованием, - тема «Ноль за поведение» (1934) Жана Виго, где школьники организуют восстание против начальства» (Roberti, 2006).

В итальянских игровых фильмах 1950-х - 1960-х между миром детей и миром взрослых ощущается непроходимая граница. Учителя - часто напыщенные педанты, а школьники - нерадивые хулиганы, не желающие приспосабливаться к школьным правилам поведения. Таковы они в «Учителе из Виджевано» (1963, режиссер Э. Петри), за исключением одного персонажа из мира взрослых, способного понимать детей. Это Антонио Момбелли, стремящийся сохранить собственную честь и достоинство профессии учителя. Однажды он идет на сделку с собственной совестью - уходит из школы, но после всех мытарств и смерти жены возвращается в школу, несмотря на «узость коллег и высокомерие директора» (Nuvoli, 2012: 113).

В итальянских фильмах о школе 1970-х отношения учеников и учителей становятся не просто более демократичными, но даже распущенными. Произошедшая в 1960-х 1970-х годах в западных странах сексуальная революция и уменьшение влияния католической церкви в итальянском обществе заметно повлияли на поведение как школьников так и учителей. Если в «Амаркорде» (1973) Ф. Феллини в воспоминаниях о своей юности рассказывал не только о страсти подростков к местной красотке Градиске, но и о «бессознательном влечении к красивому и идеальному миру, который таится где-то по ту сторону сказочно густого тумана» (Кудрявцев, 2008), то в других итальянских фильмах о школе 1970-х годов («Аппассионата» (1974, режиссер Д. Кальдероне), «Учительница» (1975, режиссер Н. Цицеро), «Частные уроки» (1975, режиссер В. де Систи), «Смешанный класс» (1976, режиссер М. Лауренти), «Учительница в колледже» (1978, режиссер М. Лауренти) и др.) демонстрировалось в основном воплощение эротических фантазий старшеклассников. В большинстве случаев в основе их сюжета путь юноши к овладению привлекательной 
учительницей, появляющейся в начале фильма и, влюбляющей в себя группу старшеклассников.

Пожалуй, самым пуританским итальянским фильмом о школьниках 1970-х годов была «Любовь и гимнастика» (1973, режиссер Л. Ф. д’Амико) (Nuvoli, 2012: 111).

В итальянском кинематографе школьной тематики в этот период, как, впрочем, и всей второй половине XX века, не получили отражения экзистенциальные проблемы юношей и девушек. Правда, намек на экзистенциальные переживания подростков есть в фильме П. Пьетранджели «У поросят есть крылья» (1977), где школьники Рокко и Антония из-за неудовлетворенности окружающим миром ищут утешения в интимной близости.

Не нашел яркого воплощения в итальянском кино и бунтарский дух 17-18-летних школьников. Разве что в «Первой ночи покоя» (1972) В. Дзурлини есть эпизод, в котором учащийся лицея, проходя по аудитории, зачитывает свой манифест: «Мы требуем права обсуждать свои проблемы; мы требуем, чтобы ... ученики выбирали совет класса и участвовали в обсуждении оценок». А в вышедшем в 1979 году фильме П.Ф. Пингиторе «Все в школу» тема студенческого бунта была представлена в комедийном жанре. В школе с учителем Пиппо Боттини происходят странные вещи. В одном эпизоде ему кажется, что учащиеся, одев на голову маски, и, вооружившись игрушечными пистолетами (Боттини они кажутся настоящими) окружили его, в другом, ученики, пробегая мимо него, срывают с него одежду, и т.п. В фильме есть даже комедийный революционер - Франко Цзеллетта.

В 1980-х годах рост уровня потребления и материального благополучия итальянцев негативно сказался на отношениях детей и родителей. В 1985 году на экраны вышел фильм П. Дель Монте «Маленький огонь». Главный герой Томази - маленький мальчик, волшебный и таинственный мир которого замечает только юная няня Мара, а его «родители, молодые и необузданные интеллектуалы, утонули в благополучии и не замечают присутствие Томази, который хочет сказать: "я существую"» (Ciccotti, 2006: 150). В другом фильме «Миньон уехала» (1988, режиссер Ф. Арчибуджи), по мнению Е. Чикотти, была показана «мелкобуржуазная семья, экономически состоятельная, где дети и подростки, растут погруженными в свое одиночество» (Ciccotti, 2006: 150). Это мнение перекликается с анализом мира итальянской молодежи и семьи 1970-х - 1980-х годов, сделанной Л. Манчино: «Родители часто отсутствуют в процессе формирования своих детей, делегируя воспитательные задачи другим... Молодые чувствуют себя все более одинокими» (Mancino, 1987: 218).

Словно в ответ на эти переживания детей и молодежи в итальянских фильмах о школе в 1990-х годах появляются персонажи, пытающиеся им помочь.

Главный герой фильма Л. Вертмюллер «Я надеюсь, что выкарабкаюсь» (1992) М. Спирелли, начиная работать учителем третьего класса в новой школе, вскоре «выясняет, что большинства мальчиков нет в классе, потому что они на работе, они помогают отцам в семейном бизнесе... Учитель собирает детей, вытаскивает их из магазинов и газетных киосков и отправляет их обратно в класс» (Ebert, 1994). Постепенно школьники начинают доверять ему доверять, и даже самый нерадивый ученик и малолетний преступник Рафаэль - в финале картины принимает его как старшего друга.

Фильм «Школа» (1995) Д. Лукетти повествует о «двух отдельных мирах» учителей и учеников, которые только время от времени находят способ встретиться друг с другом» (Rufo, 2009). В школе явно наблюдается кризис, вызванный «теми учителями ..., которые интересуются только карьерой и нечувствительны к потребностям учеников» (Rufo, 20o9). Однако среди них есть и «положительные примеры, такие как Вивальди и Маджелло, которые увлечены учебным процессом, внимательны и близки к ученикам» (Rufo, 2009).

В фильме «Приветствие профессора» (1997, режиссер Р. Милани) продолжена тема героя-одиночки, стремящегося помочь ученикам. Однако, как и в предыдущей картине, школьная атмосфера «некоммуникабельности» становится непреодолимым препятствием в реализации его стремлений.

\section{4. Результаты}

Технология герменевтического анализа итальянских художественных фильмов о школе. 
Место действия, исторический, религиозный, культурный, политический, идеологический контекст

1. Исторический контекст.

а) особенности исторического периода создания медиатекстов, условия рынка, которые способствовали замыслу, процессу создания медиатекстов, степень влияния событий того времени на медиатексты.

Италия после второй мировой войны оказалась отстающей в экономической и социальной сфере от многих европейских стран и США. Однако в первые десятилетия итальянская экономика не только преодолела кризис, но и вышла в лидеры: «на 1950-1970-е годы пришелся... период так называемого итальянского экономического чуда, когда страна обогнала по темпам прироста промышленной продукции все западноевропейские страны» (Маслова, 2014: 61).

Улучшение экономического положения, демократизация политических и социальных институтов, борьба с социальной несправедливостью привели к постепенной либерализации бывшего монархического и дикторского общества.

В 1950-х - 1960-х годах римская католическая церковь играла одну из ключевых ролей в регулировании отношений в сфере культуры. В энциклике Папы Пия XII от 1957 года «Miranda Prorsus» («Удивительный прогресс») звучит призыв создавать фильмы высокой нравственности, оказывающей положительное воспитательное воздействие на аудиторию.

Имевшая значительную поддержку населения и пользовавшаяся монополией власти христианско-демократическая партия в первые послевоенные годы вела цензурный контроль в производстве кинематографа. Хотя он был и не такой жесткий, как в Советском Союзе, но в числе нерекомендованных верующей аудитории фильмов оказалась, к примеру, «Сладкая жизнь» (1960) Ф. Феллини, а в начале 1970-х годов Организация потребителей Италии грозилась сжечь фильм Б. Бертолуччи «Последнее танго в Париже» (1972). Впрочем, это была одна из последних попыток ограничить появление на итальянском киноэкране откровенных сцен. В 1970-х - 1980-х годах итальянских кинематографистов уже не сдерживала цензура, и студии выпускали фильмы о школьниках в комедийноэротическом жанре.

В 1990-е годы Италия переживала политический кризис, связанный с коррупцией и «партократией». В фильмах школьной тематики в этот период поднимаются остросоциальные темы: авторитаризм директора и коррумпированность его подчиненных, аморфность учителей.

b) примеры исторических ссылок в данных медиатекстах.

В принятой Италией в 1947 году Конституции были закреплены права детей всех сословий на первоначальное бесплатное образование, однако обучение в лицее (третей ступени среднего образования, после которой учащиеся получают возможность поступать в университет) было доступно детям из обеспеченных семей. Частным лицам и организациям было дано право учреждать коммерческие школы и институты. (Лупенкова, 2017: 156). До середины XX века в Италии частными были только католические школы и университеты.

Бурное экономическое развитие («экономическое чудо») 1950-х - 1960-х годов и новый этап социально-политического развития Италии в демократическом и либеральном направлении, позволили возникнуть новому формату некатолических коммерческих школ. В одном из фильмов на школьную тематику - «Обнаженная... ты умрешь» (1968, режиссер А. Маргерити) - воссоздан образ коммерческой школы для обучения девушек. Большая закрытая территория учебного заведения, бассейн, ипподром, оранжереи, вымощенные булыжником дорожки, отдельные большие комнаты для проживания, напоминающие апартаменты пятизвездочных отелей - все это позволяет сделать вывод о немалом финансовом состоянии родителей, оплачивающих обучение своих дочерей, которые нежатся на солнце, катаются на лошадях, прогуливаются по ухоженным аллеям и т.п.

С момента объединения Италии в 1840-х - 1870-х годах имеющиеся отличия в экономическом и культурном уровне северных и южных областей стали поводом для формирования стереотипных мнений у самих итальянцев друг о друге. Жители севера считают южан ленивыми, необразованными и патриархальными, а жители юга видят северян заносчивыми, замкнутыми и скупыми. В современной Италии «существует огромная разница между развитым и богатым Севером и более бедным, но гордым Югом» 
(Титова, 2004: 271). Это итальянская особенность легла в основу одного из фильмов школьной тематики- «Я надеюсь, что выкарабкаюсь» (1992) Л. Вертмюллер, где сюжетная линия и отдельные сцены повествуют «о вечном конфликте Юга и Севера, противостоянии грубых, невоспитанных южан и заносчивых... северян» (Кудрявцев, 2009). По сюжету фильма учитель с Севера по ошибке направлен в одну из школ южного города Италии, где он сталкивается с невежеством местных жителей, незаконной эксплуатацией детей и безразличием взрослых к их судьбам, а его новые подопечные - младшие школьники не стесняются в выражениях, ведут себя несдержанно и вульгарно.

2. Социокультурный, идеологический, мировоззренческий, религиозный контекст

а) идеология, мировоззрение авторов данных медиатекстов в социокультурном контексте; идеология, культура мира, изображенного в медиатекстах.

В послевоенные годы одни итальянские кинематографисты изображали драматизм борьбы итальянцев с бедностью, другие показывали разлагающуюся буржуазную интеллигенцию. В начале 1960-х годов в фокусе их внимания оказались семейные отношения. Внешними причинами разрушения семьи в фильмах «Рокко и его братья» (1960, режиссер Л. Висконти), «Сладкая жизнь» (1960, режиссер Ф. Феллини), «Ночь» (1961, режиссер М. Антониони), «Развод по-итальянски» (1961, режиссер П. Джерми) были все те же скудные бытовые и материальные условия бедных и внутренняя пустота и отчуждение богатых персонажей. В 1963 году на экраны вышел фильм Э. Петри «Учитель из Виджевано», где авторы в образе школьного педагога выразили бессилие сопротивления простого и честного человека власть имущим и аристократам.

Такого рода конфликт был положен в основу сюжетов многих итальянских фильмов конца 1940-х - первой половины 1960-х. Между тем ситуация в итальянском кинематографе менялась: уже в 1960-х годах «наступившая эра продюсерской диктатуры рассматривается в Италии как важнейшая причина и одновременно как симптом кризиса... национального кино» (Кукаркин, 1966: 7). Кризис привел к уменьшению числа авторских фильмов и увеличению количества развлекательных, коммерческих картин, финансируемых американскими продюсерами и предпринимателями. Авторское кино в 1970-х годах переключилось на политические темы, а коммерческое кино - на комедийный и эротический жанры.

Появлению комедийно-эротического жанра способствовали масштабные культурные явления: молодежные протесты, массовые феминистские демонстрации, сексуальная революция в западных странах. Итальянской молодежью утверждалась индивидуальная свобода, преодолевающая культурные запреты на открытое выражение эротических желаний. Ситуация усугублялась «систематической и окончательная эрозией религиозных, моральных и идеологических убеждений» (Ferrante, 2017). К тому же «в 1971 году была проведена либерализация пропаганды контрацептивов; в 1974 году после референдума развод окончательно утвердился в Италии» (Calanca, 2011).

В итальянских фильмах школьной тематики 1970-х - 1980-х годов субъектами эротических желаний стали учащиеся лицеев, мечтающие о сексуальных связях с привлекательными молодыми учительницами. Сюжеты этих картин незамысловаты юноши тратят все свое время на то, чтобы каким-то образом привлечь внимание красоткиучительницы или увидеть ее обнаженной, а самому удачливому из них удается вступить с учительницей в интимные отношения.

Итальянский экран 1970-1980-х гг., как правило, не пытался подойти к школьной теме серьезно, однако эта тенденция изменилась в 1990-х. Сначала о состоянии детей и молодежи заговорили специалисты: психологи, социологи, преподаватели, а затем и кинематографисты.

В конце 1980-х авторитетный итальянский филолог К. Оссола сокрушался по поводу утраты интереса школьников к литературе: «сегодня мальчики сердечно ненавидят литературу и поэзию» (Ossola, 1988, c.13), но отсутствие мотивации к учебе было только одной стороной медали. В 1980-е годы социально-экономические изменения «привели к ослаблению идеологической напряженности» (Gobbo, 2017), что послужило одной из причин размывания традиционной для Италии регламентированной социальной структуры. Воспринятый молодежью новый глоток свободы был одним из поводов формирования морального релятивизма в отношении к различным сферам жизни, 
например, к интимным отношениям. По мнению Л. Томази, несмотря на то, что молодые люди в 1990-х годах считали себя верующими католиками, их субъективная культура в области сексуальной морали имела явные «противоречия между учением церкви и их реальным поведением» (Томази, 1995, с.152).

В 1990-х годах в Италии было снято три фильма на школьную тематику, которые объединяет одна особенность. В них появляется герой-одиночка, пытающийся спасти школьников от общества морального релятивизма, царящего не только среди учащихся, но и среди самих учителей. Это отчасти удается только М. Спирелли в фильме «Я надеюсь, что выкарабкаюсь». В двух других фильмах: «Школа» (1995) и «Приветствие профессора» (1997) попытки были, на наш взгляд, менее удачны.

Как и в фильме «Школа» (1995), главный герой в «Приветствии профессора» (1997) «харизматичный, разочарованный, но все же популярный среди школьников учитель, несмотря на истощенное состояние школы и его конфликт со своими коллегами, особенно с директором» (Skullerud, 2002).

b) мировоззрение людей школьного мира, изображенного в медиатекстах (пессимизм/оптимизм, успешность/неуспешность, способность управлять своей судьбой, возможность быть счастливым и пр.), иерархия ценностей согласно данному мировоззрению; ценности преобладающие в финалах данных медиатекстов; как данные медиатексты отражают, укрепляют, внушают, или формируют отношения, ценности; поведение, мифы.

Изображение школьного мира в итальянских фильмах второй половины 20 века:

- мировоззрение: у персонажей школьного возраста 1960-х годов несмотря на жесткую дисциплину, крайне ограничивающую их свободу поведения; преобладает оптимистическое мировоззрение, проявляющееся в их надежде на жизненные перспективы, в то время, как у экранных школьников 1970-х - 1990-х оптимистической мировоззрение, связано со свободой поведения.

- иерархия ценностей: для персонажей-школьников характерно стремление к удовлетворению желаний, интимной близости, самовыражение во внешнем образе, избегание трудностей в учебе (отсюда вытекает и не соотнесение своих успехов в учебе с будущими достижениями в карьере, финансовым благополучием);

- основной стереотип успеха в этом мире: привлечь к себе внимание окружающих, весело проводить досуг, добиваться расположения и интимной близости девушек/юношей (в 1970-х годы и молодых учительниц).

3. Структура и приемы повествования в данных медиатекстах

Схематично структуру, сюжет, репрезентативность, этику, особенности жанровой модификации, иконографии, характеров персонажей можно представить следующим образом:

место и время действия медиатекстов: Италия в настоящем и прошлом, городские и частные провинциальные школы, лицеи, дома, квартиры;

характерная для данных медиатекстов обстановка, предметы быта: здания коммерческих или городских школ выполнены в классическом стиле с арками, колоннами, просторными помещениями; в фильмах 1970-х годов учебные классы светлые, яркие без архитектурных излишеств, в них появляются географические карты, глобусы, макеты человеческого тела и другое наглядное оборудование для обучения; в фильмах 1990-х годов на стенах коридоров и помещений школ много рисунков и надписей; в фильмах 1960-х годов домашний быт большинства школьников скромен (маленькие помещения с серыми стенами), но единичные персонажи живут в больших и роскошных домах; начиная с 1970-х годов бытовые условия школьников становятся более комфортными: комнаты просторнее с бОльшим количеством мебели и украшений.

жанровые модификации: драма, комедия, эротическая комедия, гораздо реже - фильм ужасов (например, «Суспирия» (1977) Д. Ардженто);

(стереотипные) приемы изображения действительности: в фильмах 1960-х годов учителя изображены в несколько гротескном виде: их строгость и педантичность воспринимается как излишняя напыщенность, создаваемая для поддержания авторитета; учащиеся, чтобы не скучать на уроках, подшучивают друг над другом и над учителем; начиная с 1970-х учителя выглядят проще, менее строги в одежде и стиле речи; учащиеся 
часто ведут себя вульгарно: перебивают учителя, садятся на стол, разговаривают, эпизодически курят;

типология персонажей (черты характера, одежда, телосложение, лексика, мимика, жесты персонажей, присутствие или отсутствие стереотипной манеры репрезентации персонажей в данных медиатекстах):

- возраст персонажей: 10-70 лет;

- уровень образования: начальное, среднее, высшее;

- социальное положение, профессия: варьируется и зависит от их учебного и профессионального статуса: школьник, учитель, священнослужитель, домохозяйка и пр.;

- семейное положение персонажа: как правило, персонажи молоды и еще не успели вступить в брак;

- внешний вид, одежда, телосложение персонажа, черты его характера, лексика. До конца 1960-х годов экранные школьники носили форму: мальчики брюки (в теплое время года - шорты), рубашки; девочки -длинные платья. С начала 1970-х годов школьники стали одеваться вольно: юноши - в рубашки, свитера, джинсы, подчеркивающие и стройную фигуру, девушки - щеголяли в брюках/джинсах, коротких платьях и мини-юбках.

Школьники на итальянском экране 1960-х годов эмоциональны, активны, непосредственны, в чем-то наивны; в последующие десятилетия, сохраняя непосредственность, они стали вульгарнее и агрессивнее, а их лексика - более грубой.

существенное изменение в жизни персонажей медиатекстов:

- сюжетный вариант № 1: учащиеся не имеют мотивации к учебе. Учитель стремиться их заинтересовать.

- сюжетный вариант № 2 (возникший, начиная с 1970-х годов): в школе появляется молодая учительница, становясь объектом эротического внимания учащихся.

возникшая у персонажей проблема: нарушение привычной жизни персонажа;

поиски персонажами решения проблемы:

- персонажи-школьники пытаются измениться к лучшему - преодолеть негативные формы собственного поведения:

- попытка персонажей-школьников вступить в интимную связь с учительницей.

\section{5. Заключение}

В фильмах о школе 1960-х годов воссоздавалась атмосфера «разделения на мир детей и на взрослый мир» (Di Scianni, 2011). Школьники сдержанно реагировали на наигранновозвышенную лексику, высокомерие и кичливость учителей, в целом находясь в рамках учебной дисциплины. С начала 1970-х до начала 1980-х гг. Италию захлестнула волна коммерческого эротического кино. Юноши-старшеклассники предстали соблазнителями привлекательных учительниц, отвечающих им взаимностью. Начиная с 1990-х на экраны стали выходить авторские фильмы, анализирующие отношения учителей и учащихся, воссоздающие атмосферу отчуждения. Однако в итальянском кино иногда появлялись и персонажи, пытающиеся служить педагогическому долгу и находить подход к учащимся.

Образ учителя в итальянских фильмах школьной тематики заметно менялся. Если в 1960-х учитель был похож на педантичного тирана, кичащегося собственным статусом мудреца, вещающего вечные истины, то с наступлением 1970-х годов он стал выглядеть глупее, комичнее, агрессивнее и вульгарнее. Затем педагоги все чаще становились на экране корыстными карьеристами, не заботящимися о проблемах учащихся.

C течением времени школьники на итальянском киноэкране становились более вольнодумными и себялюбивыми. В большинстве итальянских фильмов они выражали индивидуальную свободу в различного рода протестных формах. В 1960-х годах они сопротивлялись педагогическому воздействию и авторитаризму учителей и родителей. В 1970-х - 1980-х - преодолевали культурные запреты на открытое выражение сексуальных желаний. Начиная с 1990-х, демонстрировали субъективное отношение к моральным принципам, протестовали против «абсолютной истины».

Путь школьников-персонажей к свободе сопровождался охлаждением семейных отношений. Отношения родителей с учащимися становились эпизодическими, родители равнодушно относились к их учебной деятельности и практически не участвовали в воспитании. 


\section{6. Благодарности}

Статья написана в рамках исследования при финансовой поддержке гранта Российского научного фонда (РНФ). Проект № 17-18-01001 «Школа и вуз в зеркале советских, российских и западных аудиовизуальных медиатекстов», выполняемый в Ростовском государственном экономическом университете.

\section{Литература}

Кудрявцев, 2008 - Кудрявцев, С.В. Ностальгическая сатирическая притча. Кинопоиск.py. 2008. [Электронный ресурс]. URL: https://www.kinopoisk.ru/review/832592/

Кудрявцев, 2009 - Кудрявцев, С.В. Трагикомедия. Кинопоиск.ру. 2009. [Электронный pecypc]. URL: https://www.kinopoisk.ru/review/960014/

Кукаркин, 1966 - Кукаркин, А.В. Десятая муза или десятая жертва?: об основных тенденциях в современном кино Запада. М. Знание, 1966. 32 с.

Лупенкова, 2017 - Лупенкова, Н.В. Образовательные реформы Италии: история и опыт // ИСОМ. 2017. №3-2. С. 155-162.

Маслов, 2014 - Маслова, Е.Д. Италия: образование и экономическое развитие // Современная Европа. 2014. № 4. С. 61-69.

Титова, 2004 - Титова, T.P. Итальянский язык и итальянцы / Россия и Запад: диалог культур. Сб. статей 10-ой юбилейной междунар. конференции. Вып. 12. Ч. II. М.: МГУ, 2004. C. 269-281.

Томази, 1995 - Томази, Л. Молодежь и религия в современной Италии // Социологические исследования. 1995. №10. С. 146-152.

Эко, 2005 - Эко, У. Роль читателя. Исследования по семиотике текста. СПб: Симпозиум, 2005. $502 \mathrm{c}$.

Bazalgette, 1995 - Bazalgette, C. Key Aspects of Media Education. Moscow: Association for Film Education, 1995.

Calanca, 2011 - Calanca, D. La Nuova Generazione: mode e costumi giovanili nell'Italia degli anni Settanta // Storia e Futuro, 2011. [Electronic resource]. URL: http://storiaefuturo.eu/nuovagenerazione-mode-costumi-giovanili-nellitalia-degli-anni-settanta/

Ciccotti, 2006 - Ciccotti, E. L’infanzia nel cinema // Bambini multimediali, 2006. pp. 137-162.

Di Scianni, 2011 - Di Scianni, L. Capelloni, moda, Inghilterra e Beatles: i simboli della contestazione giovanile nell'Italia degli anni Sessanta // Storia e Futuro, 2011. [Electronic resource]. URL: http://storiaefuturo.eu/capelloni-moda-inghilterra-beatles-i-simboli-contestazione-giovanilenellitalia-degli-anni-sessanta/

Ebert, 1994 - Ebert, R. Ciao, Professore! // Sun-Times. 29.07.1994. [Electronic resource]. URL: https://www.rogerebert.com/reviews/ciao-professore-1994

Ferrante, 2017 - Ferrante M. I giovani nella seconda metà del novecento // CulturaCattolica.it, 2017. [Electronic resource]. URL: https://www.culturacattolica.it/educazione/strumenti-per-lascuola/la-condizione-giovanile-nel-90o/i-giovani-nella-seconda-met\%C3\%Ao-del-novecento

Gobbo, 2017 - Gobbo, D. Società, economia e politica negli anni '8o // Storia e Futuro, 2017. [Electronic resource]. URL: http://storiaefuturo.eu/la-legge-266-91-lungo-processo-riconoscimentodel-volontariato/

Mancino, 1987 - Mancino, L. Modelli di cultura e immagini sociali negli anni '70 e '80, 1987, XXIV, 1-6, p. II. pp. 207-218. [Electronic resource]. URL: http://www.bibliotecaprovinciale.foggia.it/ capitanata/1987/1987pdf_parte2/1987_pII_207-218_Mancino.pdf

Nuvoli, 2012 - Nuvoli, G. La scuola italiana al cinema, in Leggere la scuola, Atti del Convegno Milano da leggere, a cura di B. Peroni. Milano, Unicopli. 2012. pp. 109-129. [Electronic resource]. URL: https://air.unimi.it/retrieve/handle/2434/206048/219363/Giuliana\%2oNuvoli,\%20La\%20 scuola\%20italiana\%20al\%20cinema\%20(con\%20immagini).pdf

Ossola, 1988 - Ossola, C. Quale spazio per l'educazione letteraria nella scuola media? // Scuola Ticinese. 1988. 13-17.

Roberti, 2006 - Roberti, B. Spettacoli per ragazzi: cinema // Enciclopedia dei ragazzi. 2006. [Electronic resource]. URL: http://www.treccani.it/enciclopedia/spettacoli-per-ragazzi-cinema_ \%28Enciclopedia-dei-ragazzi\%29/

Rufo, 2009 - Rufo, F. La scuola // mymovies.it. 2009. [Electronic resource]. URL: http://www.mymovies.it/dizionario/recensione.asp?id=21909 
Silverblatt, 2001 - Silverblatt, A. Media Literacy. Westport, Connecticut - London: Praeger, 2001, 449 p.

Skullerud, 2002 - Skullerud, $K$. Interesting film about a high school teacher fighting his inner demons! // IMDB, 2002. [Electronic resource]. URL: http://www.imdb.com/title/tto122385/?ref_= nm_flmg_dr_2O

\section{References}

Bazalgette, 1995 - Bazalgette, C. (1995). Key Aspects of Media Education. Moscow: Association for Film Education.

Calanca, 2011 - Calanca, D. (2011). La Nuova Generazione: mode e costumi giovanili nell'Italia degli anni Settanta. Storia e Futuro. [Electronic resource]. URL: http://storiaefuturo .eu/nuova-generazione-mode-costumi-giovanili-nellitalia-degli-anni-settanta/

Ciccotti, 2006 - Ciccotti, E. (2006). L’infanzia nel cinema // Bambini multimediali. pp. 137-162.

Di Scianni, 2011 - Di Scianni, L. (2011). Capelloni, moda, Inghilterra e Beatles: i simboli della contestazione giovanile nell'Italia degli anni Sessanta. Storia e Futuro. [Electronic resource]. URL: http://storiaefuturo.eu/capelloni-moda-inghilterra-beatles-i-simboli-contestazione-giovanilenellitalia-degli-anni-sessanta/

Eko, 2005 - Eko, U. (2005). Rol' chitatelya. Issledovaniya po semiotike teksta [The role of the reader. Research on the semiotics of the text]. SPb: Simpozium, 502 p. [in Russian]

Ebert, 1994 - Ebert, R. (1994). Ciao, Professore! Sun-Times. 29.07.1994. [Electronic resource]. URL: https://www.rogerebert.com/reviews/ciao-professore-1994

Ferrante, 2017 - Ferrante, M. (2017). I giovani nella seconda metà del novecento. CulturaCattolica.it. [Electronic resource]. URL: https://www.culturacattolica.it/educazione/ strumenti-per-la-scuola/la-condizione-giovanile-nel-90o/i-giovani-nella-seconda-met\%C3\%Ao-delnovecento

Gobbo, 2017 - Gobbo, D. (2017). Società, economia e politica negli anni '8o. Storia e Futuro. [Electronic resource]. URL: http://storiaefuturo.eu/la-legge-266-91-lungo-processoriconoscimento-del-volontariato/

Kudryavtsev, 2008 - Kudryavtsev, S.V. (2008). Nostal'gicheskaya satiricheskaya pritcha [Nostalgic satirical parable]. Filmsearch.ru. [Electronic resource]. URL: https://www.kinopoisk.ru/review/832592/ [in Russian]

Kudryavtsev, 2009 - Kudryavtsev, S.V. (2009). Tragikomediya [Tragicomedy]. Filmsearch.ru. [Electronic resource]. URL: https://www.kinopoisk.ru/review/960014/ [in Russian]

Kukarkin, 1966 - Kukarkin, A.V. (1966). Desyataya muza ili desyataya zhertva?: ob osnovnykh tendentsiyakh v sovremennom kino Zapada [The tenth muse or the tenth sacrifice?: about the main trends in contemporary Western cinema]. Moscow: Knowledge, 32 p. [in Russian]

Lupenkova, 2017 - Lupenkova, N.V. (2017). Obrazovatel'nye reformy Italii: istoriya i opyt [Italy's educational reforms: history and experience]. ISOM. № 3-2, pp. 155-162. [in Russian]

Mancino, 1987 - Mancino, L. (1987). Modelli di cultura e immagini sociali negli anni '70 e '80, XXIV, 1-6, p. II. pp. 207-218. [Electronic resource]. URL: http://www.bibliotecaprovinciale.foggia.it/ capitanata/1987/1987pdf_parte2/1987_pII_207-218_Mancino.pdf

Maslova, 2014 - Maslova, E.D. (2014). Italiya: obrazovanie i ekonomicheskoe razvitie [Italy: education and economic development]. Modern Europe. № 4, pp. 61-69. [in Russian]

Nuvoli, 2012 - Nuvoli, G. (2012). La scuola italiana al cinema, in Leggere la scuola, Atti del Convegno Milano da leggere, a cura di B. Peroni. Milano, Unicopli. pp. 109-129. [Electronic resource]. URL: https://air.unimi.it/retrieve/handle/2434/206048/219363/Giuliana\%20Nuvoli, \%20La\%20scuola\%20italiana\%20al\%20cinema\%20(con\%20immagini).pdf

Ossola, 1988 - Ossola, C. (1988). Quale spazio per l'educazione letteraria nella scuola media? Scuola Ticinese. 13-17.

Roberti, 2006 - Roberti, B. (2006). Spettacoli per ragazzi: cinema. Enciclopedia dei ragazzi.

[Electronic resource]. URL: http://www.treccani.it/enciclopedia/spettacoli-per-ragazzi-cinema_ \%28Enciclopedia-dei-ragazzi\%29/

Rufo, 2009 - Rufo, F. (2009). La scuola. mymovies.it. [Electronic resource]. URL: http://www.mymovies.it/dizionario/recensione.asp?id=21909

Silverblatt, 2001 - Silverblatt, A. (2001). Media Literacy. Westport, Connecticut - London: Praeger, $449 \mathrm{p}$. 
Skullerud, 2002 - Skullerud, $K$. (2002). Interesting film about a high school teacher fighting his inner demons! IMDB. [Electronic resource]. URL: http://www.imdb.com/title/tto122385/?ref _ $=\mathrm{nm} \_$flmg_dr_2O

Titova, 2004 - Titova, T.P. (2004). Ital'yanskii yazyk i ital'yantsy [Italian language and Italians]. Russia and the West: a dialogue of cultures. The collection of articles of the 1oth jubilee international conference. Issue 12, Part II. Moscow: Moscow State University, pp. 269-281. [in Russian]

Tomazi, 1995 - Tomazi, L. (1995). Molodezh' i religiya v sovremennoi Italii [Youth and religion in modern Italy]. Sociological research. № 10. pp. 146-152. [in Russian]

\section{Герменевтический анализ итальянских игровых фильмов о школе}

Роман Викторович Сальный а, *

a Ростовский государственный экономический университет, Российская Федерация

Аннотация. Проведенный в статье анализ позволяет проследить трансформацию образов школьника, учителя и семейных отношений на итальянском киноэкране. Решению этой задачи способствовали: изучение культурного, социального, политического контекста и экономического состояния; анализ идеологии, в том числе влияния католической религии на кинематограф; анализ жанровых стереотипов.

В статье дается характеристика социокультурных преобразований в Италии, анализируется их влияние на детско-родительские отношения, мировоззрение школьников и их отношения к традициям и ценностям. Представлены исторические примеры, отражающие смену идеологии, расшатывание патриархальных устоев, изменение роли женщины, сексуальную революцию, оказавшие колоссальное влияние на трансформацию образа школьника в итальянском кинематографе. Приведены примеры репрезентации авторами образов итальянских школьников в кино в различных жанровых формах: от авторских драматических до коммерческих комедийно-эротических.

В статье делается вывод о том, что с течением времени школьники на итальянском киноэкране становились более вольнодумными и себялюбивыми. В большинстве итальянских фильмов они выражали индивидуальную свободу в различного рода протестных формах. В 1960-х годах они сопротивлялись педагогическому воздействию и авторитаризму учителей и родителей. В 1970-1980-х гг. преодолевали культурные запреты на открытое выражение сексуальных желаний. В 1990-х годах демонстрировали субъективное отношение к моральным принципам, протестовали против «абсолютной истины».

Ключевые слова: кино, Италия, школа, герменевтический анализ, медиаобразование, репрезентации, ценности, культура.

\footnotetext{
${ }^{*}$ Корреспондирующий автор

Адреса электронной почты: roman_tag82@mail.ru (Р.В.Сальный)
} 